OPEN ACCESS

Edited by:

Ann Dowker,

University of Oxford, UK

Reviewed by:

Jo Van Herwegen,

Kingston University, UK

Mila Vulchanova,

Norwegian University of Science and

Technology, Norway

*Correspondence:

Sergio Melogno

sergio.melogno@uniroma1.it

Specialty section:

This article was submitted to Developmental Psychology,

a section of the journal

Frontiers in Psychology

Received: 15 July 2016 Accepted: 12 December 2016 Published: 04 January 2017

Citation:

Melogno S, Pinto MA and Orsolini M (2017) Novel Metaphors

Comprehension in a Child with

High-Functioning Autism Spectrum

Disorder: A Study on Assessment and

Treatment. Front. Psychol. 7:2004

doi: 10.3389/fpsyg.2016.02004

\section{Novel Metaphors Comprehension in a Child with High-Functioning Autism Spectrum Disorder: A Study on Assessment and Treatment}

\author{
Sergio Melogno *, Maria A. Pinto and Margherita Orsolini \\ Dipartimento di Psicologia dei Processi di Sviluppo e Socializzazione, "Sapienza," Università di Roma, Rome, Italy
}

Until the first decade of the current millennium, the literature on metaphor comprehension highlighted typical difficulties in children with high-functioning Autism Spectrum Disorder (ASD). More recently, some scholars have devised special programs for enhancing the capability of understanding metaphors in these children. This article presents a case study based on a treatment aiming at enhancing novel metaphor comprehension in a high-functioning child with ASD. M.M., a pseudoacronym for an 8;10 year-old boy, diagnosed with high-functioning ASD, was first assessed with a metaphor comprehension test. This testing (at time T0) highlighted a rigid refusal of metaphors and a marked tendency toward literal interpretation. A baseline treatment (8 sessions of 45-60 min each, twice a week) was implemented, based on a series of recognition, denomination and emotion comprehension activities. M.M.'s metaphor comprehension was assessed a second time (T1), followed by the experimental treatment (same duration and frequency as the first one), specifically focused on metaphor comprehension. Finally, a third assessment of metaphor comprehension took place (T2), followed by a last assessment 4 months later (follow-up, T3). The comparison between the performances at the metaphor comprehension test across the four assessments, from TO to T3, showed that the baseline treatment produced no effect at all, whereas a significant improvement appeared at T2, just after the experimental treatment, later confirmed at the follow up. Both quantitative and qualitative results showed an evident improvement in the way M.M. handled the semantic issues posed by the metaphors of the test, in line with the strategies he was taught during the treatment.

Keywords: novel metaphors, comprehension, autism spectrum disorder, high functioning, assessment, treatment

\section{INTRODUCTION}

Metaphor comprehension difficulties in high-functioning children with Autism Spectrum Disorder (ASD, henceforth) are well documented (Happé, 1993, 1995; Norbury, 2005; Rundblad and Annaz, 2010; Melogno et al., 2012a,c; Kasirer and Mashal, 2014; Vulchanova et al., 2015). Faced with metaphors, children with ASD tend to remain firmly anchored to literal interpretations. For instance, if one of two children say "Autumn leaves are butterflies," the listener might interpret the relationship between the two terms ( $X=$ autumn leaves, $Y=$ butterflies) literally, i.e., as an identity, and fails to understand the speaker's intended meaning. In this case, he/she can only reject 
the sentence because autumn leaves are clearly not butterflies. However, if the listener realizes that what the speaker means is "Autumn leaves are like butterflies," he/she can compare the two terms and look for a shared property, in this case, the movement or the shape, the color, etc., and come to a plausible interpretation of the metaphor.

In developmental literature, metaphors like the one above are called sensory (Winner, 1998), because they combine terms pertaining to the same physical sphere, in which the link between the two parts of the metaphor relies on functional or perceptual properties (color, shape, etc.). Other metaphors are called physico-psychological (Winner, 1998) because the two terms that compose them pertain to the physical and the psychological domain (e.g., "Juliet is the sun"). Another relevant distinction is between dead and novel metaphors, the former being those we conventionally use (e.g., "He is a snake"), and the latter being created on the spot (e.g., "Autumn leaves are butterflies").

Based on empirical evidence, 6-7 year olds typically developing children are already able to guess that metaphors are a deliberate means to communicate and not merely a mistake or a lie (Demorest et al., 1983). The first signs of metaphorical understanding can even be found at the age of 4 (Keil, 1986; Gentner, 1988), although this ability is gradually refined later on (Vosniadou, 1987; Declercq et al., 2010).

Research on metaphor comprehension has found lower performance in high functioning children with ASD than in neurotypical children (Happé, 1993, 1995; Dennis et al., 2001; Martin and McDonald, 2004; Norbury, 2005; Rundblad and Annaz, 2010), particularly in a subgroup characterized by language difficulties (Norbury, 2005; Gernsbacher and PripasKapit, 2012). How to explain impaired metaphor comprehension in children with ASD is still an open issue. Some scholars (Happé, 1993, 1995) claim that a deficit in the theory of mind would undermine the comprehension of what the speaker means ( $\mathrm{X}$ is like $\mathrm{Y}$ ) beyond what the speaker says ( $\mathrm{X}$ is $\mathrm{Y}$ ). However, Norbury (2005) showed that theory of mind is a "necessary but not sufficient" factor to metaphor comprehension and that specific language competences such as semantic knowledge are also necessary. Another possible explanation comes from the tendency (Weak Central Coherence) shown by people with ASD to process information locally rather than globally. This could have negative consequences on the ability to use sentence context to disambiguate meaning (Rundblad and Annaz, 2010). The efficiency of executive functions is another factor that may account for the difficulties encountered by children with ASD (Mashal and Kasirer, 2011; Kasirer and Mashal, 2014).

Recent research based on experimental and case studies has raised the question of whether metaphor comprehension can be enhanced in children with ASD (Mashal and Kasirer, 2011; Persicke et al., 2012; Melogno et al., 2012b). Adapting a procedure used in brain lesions rehabilitation (Lundgren et al., 2006), Mashal and Kasirer (2011) created thinking maps to train children in comparing the two terms of a metaphor. In a similar vein, Persicke et al. (2012) devised a procedure to help children with ASD in analyzing metaphors embedded in stories. Step by step, children were guided toward rejecting irrelevant semantic features and abstracting the relevant ones. The encouraging results of these studies suggest that teaching children with ASD how to compare terms in a metaphor can enhance metaphor comprehension. On the other hand, research on this type of intervention could illuminate the role of the many factors invoked so far to explain difficulties in metaphor comprehension in children with ASD. For instance, a training focused on semantic knowledge could test the relevance of this factor, as claimed by Norbury (2005).

The present case study extends the training method set out by Mashal and Kasirer (2011) by including renaming exercises aimed at enhancing semantic flexibility and adult-child interaction aimed at stimulating metalinguistic explanations.

\section{BACKGROUND}

M.M. is a high functioning child with ASD (American Psychiatric Association, 2013) who came to consultation in a clinical center on developmental disabilities when he was 8 years and 10 months and was diagnosed with Asperger Syndrome based on DSM IV-TR (American Psychiatric Association, 2000) criteria. The procedure involved the Autism Diagnostic Observation Schedule (ADOS; Lord et al., 2000), the Krug Asperger Disorder Index (KADI; Krug and Arick, 2003) and the Social Responsiveness Scale (Constantino and Gruber, 2002).

M.M. had fluent language but relevant difficulties in managing interactions. Namely, he tended to direct conversation toward his preferred topics on a particularly erudite mode. His parents also reported that M.M. took things too literally and didn't understand the real meaning of the conversation. M.M.'s rigid interpretation of language usages were paralleled by other forms of rigidity in behavior, at home and school, that could be observed in everyday ritualistic sequences. M.M.'s intellectual level was within normal range (Total IQ $=110$ ), as emerged from clinical assessment (WISC III, Wechsler, 1991) ${ }^{1}$, with a Verbal IQ of 115 and a Performance IQ of 103. Performances within norms were expected in grammar and in lexical competencies, which was confirmed by the Test of Reception of Grammar (TROG-2; Bishop, 2003; standard score: 107) and by the Peabody Picture Vocabulary Test (PPVT; Dunn and Dunn, 1981; standard score: 115). On the other hand, based on the diagnosis, a drop in metaphor comprehension was expected, which was also confirmed by a subtest assessing figurative language (APL Medea; Lorusso, 2007). In the first part of this subtest ("verbal metaphors"), the child has to listen to either a metaphorical sentence (e.g., "Mark is a lion"), or an idiomatic expression and must explain its meaning; in the second part ("visual metaphors"), the child has to listen to an idiomatic expression (e.g. "You have your head in the clouds"), and must indicate the picture that matches the appropriate meaning choosing among four possibilities. Seven times out of 8, M.M. gave a literal interpretation.

In the Theory of mind and Affect recognition tests of NEPSY II (Developmental Neuropsychological Assessment; Korkman

${ }^{1}$ At the time of this study, WISC III was the only version of the Wechsler scales available in Italy. 
et al., 2007), difficulties in mentalization and emotion recognition were expected, which were confirmed by low performance in the first test (scaled score: 6) and impaired performance in the other (scaled score: 4 ).

\section{DISCUSSION}

\section{The Research Design}

After approval from the Ethics Committee of the Dipartimento di Pediatria e Neuropsichiatria Infantile ("Sapienza" University of Rome; Department of Pediatrics and Child Neuropsychiatry, "Sapienza" Univ. of Rome) we asked an informed consent to M.M.'s parents who accepted to have their child involved in a treatment. M.M. himself consented verbally.

After clinical diagnosis, M.M.'s metaphor comprehension was first assessed with a specific test (Time 0). Then, M.M. was engaged in a baseline treatment focused on Theory of Mind (8 sessions of 45-60 min each, twice a week) and assessed a second time with a metaphor comprehension test (T1). Then an experimental treatment followed (same duration and frequency as the baseline one) targeting metaphor comprehension. Finally, a third assessment of metaphor comprehension took place (T2), followed by a follow-up assessment 4 months later (follow-up, T3).

\section{Testing the Treatment Effects: Metaphor Comprehension Assessment}

Considering the M.M.'s difficulties in non-literal understanding, we chose the Junior Metaphor Comprehension Test (Henceforth, Jnr MCT, Pinto et al., 2008), an Italian instrument validated for 4-6-year-old children. The test assesses the ability to explain the meaning of 12 metaphors included in sentences, and 13 metaphors contextualized in four stories. Nearly all of these metaphors are "sensory," e.g." "The moon is a light bulb," where "moon" pertains to the domain of "celestial bodies" and "light bulb" to that of "electric devices."

The coding system is based on a three-step scale.

A score of 0 is assigned when the child declares he/she just does'nt know (elusion), or refuses the possibility of using words metaphorically (refusal), or interprets the metaphor literally (literal interpretation).

A score of 1 is assigned when a semantic feature common to both terms of the metaphor is identified, i.e., a relevant common ground, based on functional or perceptual characteristics (identification of a relevant semantic ground).

A score of 2 is assigned when the explanation considers both differences and resemblances between the two terms of the metaphor (identification of an elaborated ground). The maximum score of the Jnr MCT is 50.

Jnr MCT has high reliability, as measured by Cronbach'alpha (0.860), high test-retest correlations ( $\mathrm{r}$-tt:0.848), and high interrater agreement, as measured by Cohen's K ( 0.73 for the 5 year olds and 0.74 for the 6 year olds).

In the follow-up assessment we administered both the Jnr MCT and the APL-Medea's subtest assessing figurative language ${ }^{2}$.

\footnotetext{
${ }^{2} \mathrm{~A}$ psychologist trained to administer the MCT and the APL Medea was responsible for the administration and blind to all the issues concerning the intervention.
}

\section{Baseline and Experimental Training}

The baseline training involved the child in watching videoclips together with the adult, and in a subsequent discussion that stimulated Theory of Mind. The child was asked to identify the visual cues of a character's emotion, name the targeted emotion, and infer the characters' mental states. The experimental training was based on the following hypotheses: (a) novel metaphors generate a cognitive conflict, as the metaphorical meaning conflicts with the literal one; (b) a child with ASD can approach such a conflict as a problem-solving activity, by analyzing meanings on explicit grounds; (c) inhibiting a literal interpretation, switching from one semantic feature to another, considering a whole discourse context to comprehend a sentence, are all processes that can be taught to children with ASD. Based on these hypotheses, three main activities were implemented. The first activity, " $\mathrm{X}$ is like $\mathrm{Y}$ heuristic" (strategy 1), consisted of exercises training the child to inhibit a literal interpretation, change a metaphor into the corresponding simile ("X is like $\mathrm{Y}$ ") and use thinking maps to search for semantic similarities between $\mathrm{X}$ and $\mathrm{Y}$ (strategy 2, Comparative strategy. Table 1). In the second activity (Table 2), the child was asked to use unconventional labels to rename objects or images. When renaming concerned associates (flour re-named as bread) the adult provided examples of metaphorical labels (flour re-named as snow).

The third activity were story-matching exercises where the child had to listen to short stories and then choose between two different metaphorical sentences to conclude the story (Table 2). The experimental training was implemented in two different phases, in 8 sessions of 45-60 min, twice a week, using novel sensory metaphors. Each session of the first phase (2 weeks) included one $X$ is like $Y$ exercise, explained and modeled by the therapist (SM), then one exercise of joint construction of metaphorical meaning, and two exercises of renaming. The $X$ is like $Y$ heuristic was consolidated through joint construction and autonomous activities in phase 2 , which also included storymatching exercises.

In the whole, the child was involved in 16 " $\mathrm{X}$ is like $\mathrm{Y}$," 48 renaming and 12 story-matching exercises. None of the metaphors used for the assessment was included in the exercises.

\section{RESULTS}

Table $3(\mathrm{~A}, \mathrm{~B})$ shows the changes in M.M.'s performance at the Jnr $\mathrm{MCT}$ as a function of the different assessment phases.

At T0, M.M.'s performance was lower than that of a 6-yearold typically developing child. In particular, 0 level answers were prevalent (60\%), and mainly consisted of refusals ("It's not true," "It can't be," "It doesn't exist"). The other $40 \%$ was entirely at level 1 (relevant basic ground between the two metaphor terms).

At T1, after the baseline treatment, the distribution of percentages of answers by levels was nearly identical to that obtained at T0. At T2, after the experimental training, M.M.'s 0 level answers nearly disappeared, level 2 answers (elaborated ground between the two terms of the metaphor) were produced for the first time and prevailed on level 1 answers. At T3, the total Jnr MCT's score was further increased and higher compared to 6 -year old typically developing children. The massive decrease of 
TABLE 1 | Examples of activities with the $X$ is like $Y$ heuristic.

\section{Example of modeling}

The adult read the sentence:"Skyscrapers are the city's giraffes"

Strategy 1: "Is like strategy"
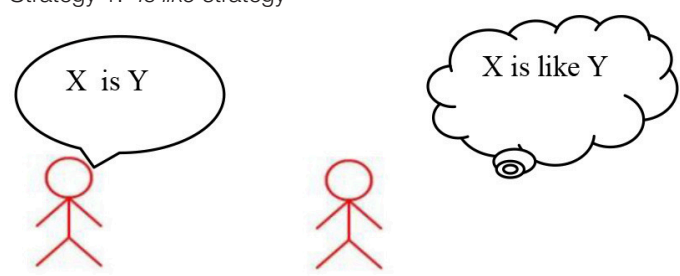

If someone says "skyscrapers are the city's giraffes," people who listen to that sentence know that skyscrapers simply cannot be giraffes.

Skyscrapers are buildings and giraffes are animals. But, to understand what is meant by this sentence I may use my first strategy with cards. I will replace $X$ with $Y$ and add "is like." Then, the sentence becomes skyscrapers are like giraffes.
Strategy 2: Comparative strategy

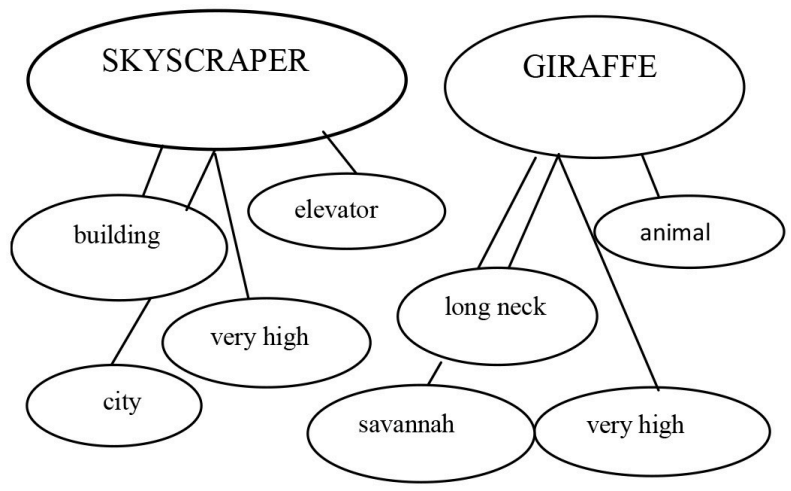

Metalinguistic reflection
Now, I will use my second strategy. I'll be thinking of the characteristics of the skyscrapers and write them down here in my thinking map. Then, I'll write that skyscrapers are buildings, that they are very high, they have elevators, etc. Now, it's giraffes' turn. I'll be thinking of the characteristics of the giraffes and write them down in my map. Giraffes are animals, they are very high, have a long neck, they live in savannahs, etc. Right.

Now, I'll see which characteristics are appropriate for both skyscrapers and giraffes. For instance, "building" is appropriate for skyscraper but has nothing to do with giraffes, then l'll reject it......."Very high" goes for both, then, l'll accept it as an appropriate characteristic. Skyscrapers and giraffes are both very high.
Example of joint construction

Strategy 1: "Is like strategy"
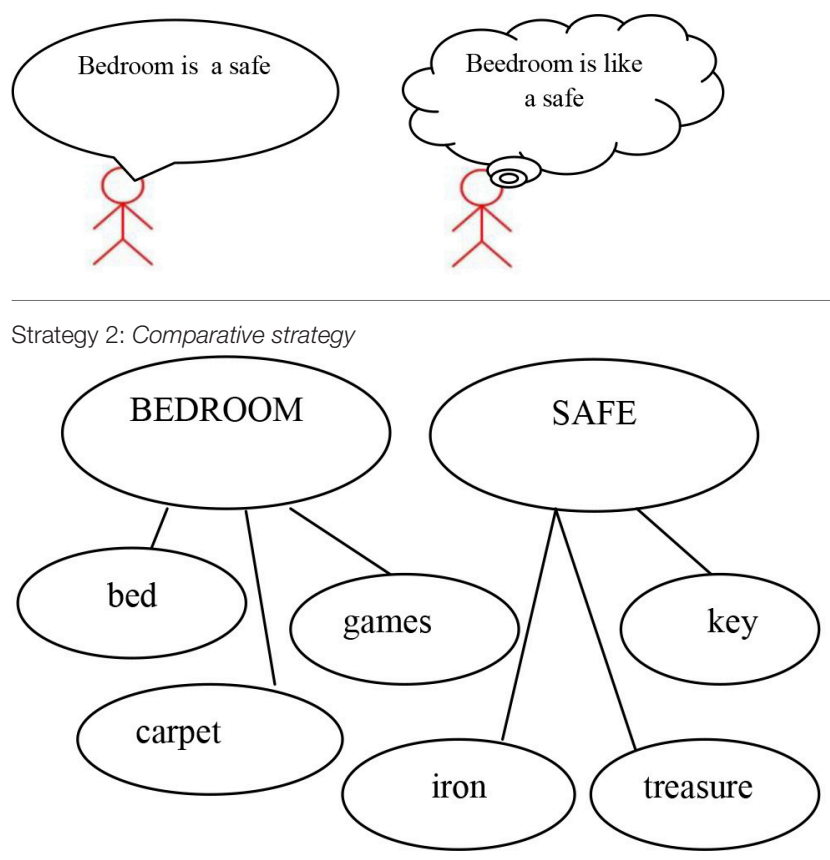

Then, we may state that the guy who said "skyscrapers are giraffes" actually meant that skyscrapers are the highest buildings in a city just as giraffes are the highest animals in a savannah. The word "giraffe" replaces another one, in this case "very high," because it expresses the meaning of being very high.
Adult: "What does this sentence mean: Bedroom is a safe ?" M.M. "Bedroom is like a safe"

Adult: "Ok, shall we use strategy 1 and write down the new sentence in the bubble?" 


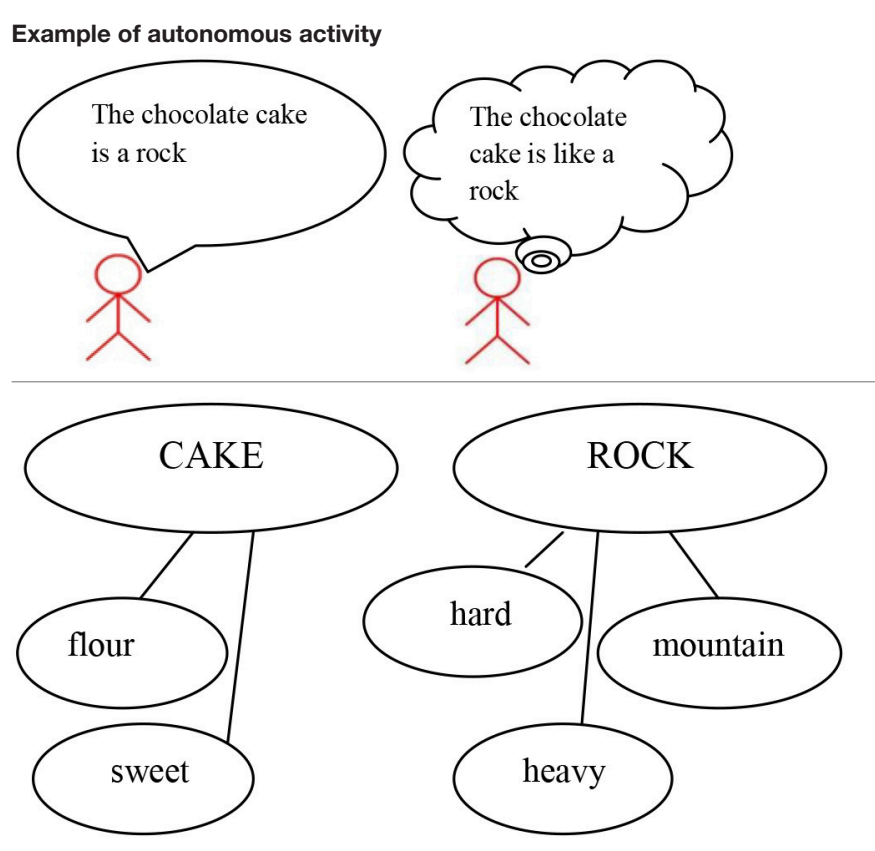

"The chocolate cake is a rock"

The child had to insert the sentence in the bubbles using strategy 1 (written exercise) like in the example in the left column.

level 0 answers was confirmed, and a further increase of level 2 answers was observed.

M.M.'s answers at the item "The scarf of the sky is colorful" across the four testing times significantly show his qualitative improvements in processing the metaphors of the test. At T0 and at T1, the child stated unconditionally: "It's not true! The sky cannot have scarves!" (refusal). After the treatment, at T2, the answer was more complex and accurate. "I don't have a clue of what it might be, it might be the clouds or the mountains...... it's the rainbow!." For the first time, M.M. envisaged more than one interpretation, and moved from a negative certitude (X cannot be $\mathrm{Y}$ ) toward a plurality of possible meanings (X might be $\mathrm{Y}$ or $\mathrm{Z}$ ), and eventually came to a plausible metaphorical interpretation (X can be Y). At T3, the child's answer was: "The milky way is the colorful scarf of the sky... because planets are made of different materials and each has a color. For example, Mars'colour is red... Uranus'colour is blue... and the Earth's color is a mixture between blue, which is the sea, and green... the grass.... on the soil, which is brown." M.M.'s evolution is very evident. He did not give up his typical erudite mode; rather, he used it for explaining linguistic meanings ("because") instead of asserting things. In this case, M.M. provided an explanation of a semantic association between the "colorful scarf of the sky" and the "milky way," which is itself a novel metaphor.

To test whether there were significant differences between total scores at different testing times (T0-T3), we calculated the standard error measurement. The results showed only one significant difference, that between $\mathrm{T} 1$ and $\mathrm{T} 2\left(\mathrm{~S}_{e}: 4.6764\right.$, significant at $p<0.05$ level). This confirms that the only significant improvement in M.M.'s performance at the Jnr MCT took place after the experimental training. In addition to the Jnr MCT, in the follow-up assessment the APL- Medea, already used in the diagnosis, was also administered. As shown in Figure 1, M.M. remarkably improved both in verbal and visual metaphors. The results were within norms.

\section{CONCLUDING REMARKS}

From the initial diagnosis to the follow-up assessment M.M. moved from 0 to 1 correct answer for visual metaphors and from one level 1 score to two level 2 scores for verbal metaphors.

The aim of this study was to analyze the effectiveness of an experimental treatment on the comprehension of novel metaphors in M.M., a child with ASD.

Enhancing M.M.'s capability of handling novel metaphors was particularly challenging as the child came to consultation with a very assertive and rigid approach to language use. The originality of the treatment was to apply a multi-step explicit linguistic procedure. At first, a metaphor that could appear as an absurdity (X is $\mathrm{Y}$ ) was transformed into a more acceptable sentence ( $\mathrm{X}$ is like $\mathrm{Y}$ ); then, the semantic features likely to provide a common ground between the two terms of the metaphor were identified, and on these grounds, a plausible interpretation was constructed. 
TABLE 2 | Examples of renaming and story-matching activities.

\section{Renaming}

The adult showed M.M. a signaling disk $(X)$ and asked him to rename it.

M.M.: "A lollipop."

If the child had renamed the object in a non-metaphorical way (e.g., "flour" renamed as "bread," or "bag"), the adult might have proposed an appropriate solution attributable to another child. "You know, another child told me so: "flour"-"snow."

The adult asked M.M. to justify the new label (e.g., "lollipop") chosen for renaming.

M.M: "It has the same round shape. The color can be red as a strawberry-flavored lollipop, or green as mint-flavored lollipop."

M.M chose the image that matched the new label.

The adult asked M.M to select or draw a picture that matched the label chosen for renaming.

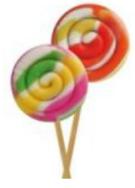

The adult asked M.M to phrase the association between the object $(X)$ and the label he chose $(Y)$ as a " $X$ is $Y$ " type of metaphor.
M.M.: "The signaling disk is a mint-and-strawberry flavored lollipop."

M.M. chose the appropriate alternative. ("Alice is a ladybug").

The adult told M.M. the following story:

"At school, the pupils are lining up to enter into the classroom. Alice is the

smallest child of the group...."

Which one of the following endings of the story is the most appropriate, "Alice is

a ladybug" or "Alice is a giraffe" ?

TABLE 3 | Raw (subparts and total) and standardized scores* at each testing time (A); Frequencies and percentages of different levels of answers at each testing time (B).

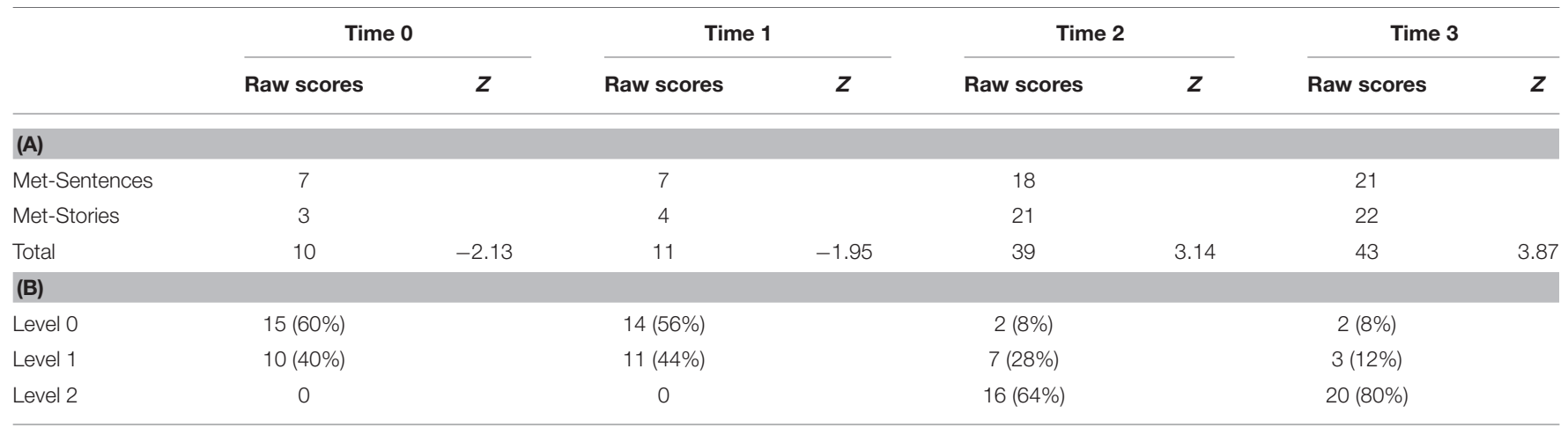

*Standardized scores are computed on the total correct answers.

After this experimental training, the child started handling the items of the Jnr MCT in a completely different manner. Although these items had nothing in common with the linguistic materials of the treatment, M.M.'s approach became at the same time more flexible (e.g., both the "rainbow" and the "milky way" could be conceived as "colorful parts of the sky") and more consistent in his explanations.

It might be argued that, after four administrations of the same test, the child had learnt the acceptable answers. However, various evidences suggest that M.M.'s improvements with novel metaphors comprehension cannot be interpreted as a result of test repetition. First, the child never received a feedback on what was a good performance at the test, so he could not know whether his answers had improved or not. Second, what the test assesses is not the number of right answers, but the number of well grounded explanations of metaphors. Third, M.M. remarkably improved also in a subtest that was administered in the diagnostic phase and at the follow-up but not in the intermediate testing phases (APL-Medea; Lorusso, 2007). As 

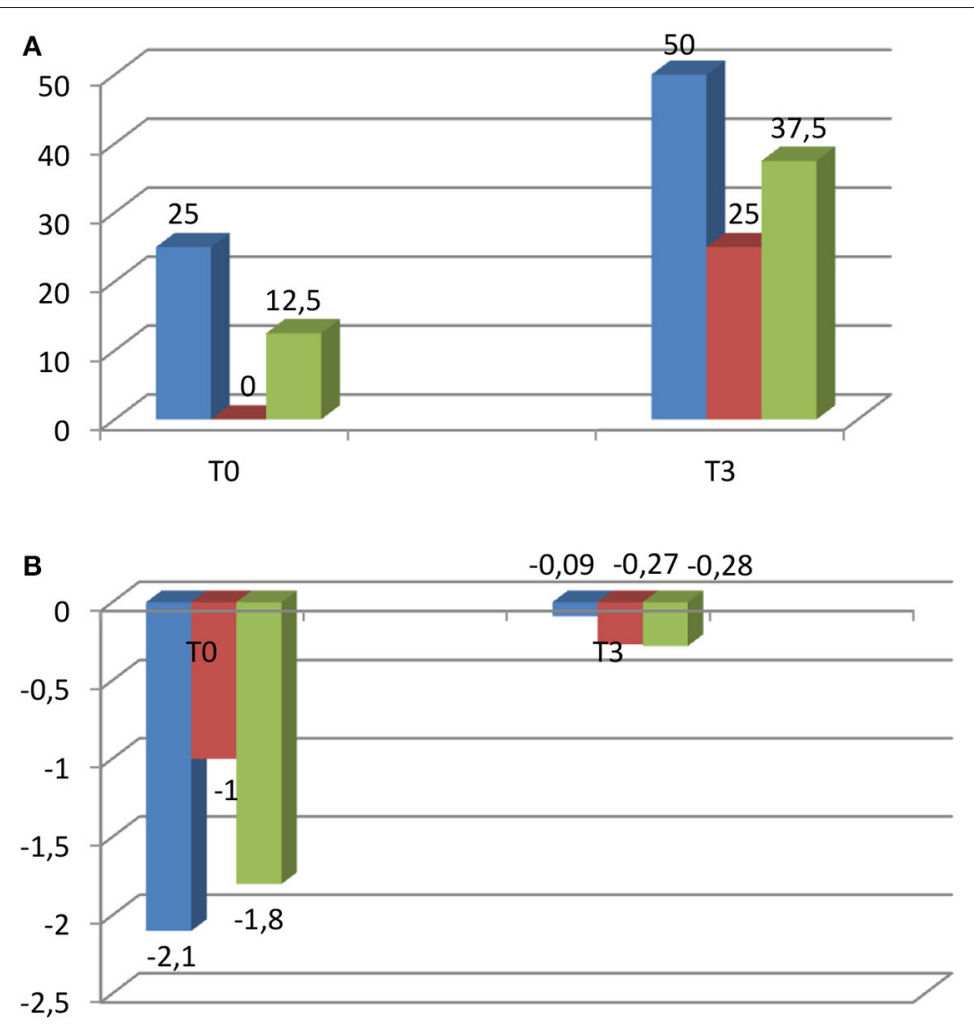

\section{Verbal metaphors \\ - Visual metaphors \\ Total}

FIGURE 1 | Results at the APL test. (A) Percentage of correct answers for verbal and visual metaphors at the APL test at T0 and T3 ${ }^{3}$. (B) $)^{4}$ Standardized scores of correct answers for verbal and visual metaphors at the APL test at TO and T3.

the items of this subtest are mostly idioms, not expressed in the "X is $\mathrm{Y}$ " form used in the treatment, we may argue that our experimental training generated a "near transfer effect" which enhanced the general capability of handling metaphors. Thus, our study, in line with the results of previous research (Mashal and Kasirer, 2011; Persicke et al., 2012) indicates that it is possible to teach explicit procedures to enhance metaphor comprehension in children with ASD. In addition, the effectiveness of the experimental treatment, compared to the ineffectiveness of the training based on Theory of Mind suggests that the key factors to metaphor comprehension in this type of children (Norbury, 2005) are specifically linguistic and semantic. Actually, the child was trained to analyze both semantic similarities and differences between meanings pertaining to completely distinct semantic areas (e.g., sky and scarf)

We believe our findings contribute to the theoretical debate about novel metaphors comprehension in children with ASD.

We also speculate that a training centered upon the interactive construction of thinking maps between adult and child would enhance children's capability of producing semantic explanations of novel metaphors even at a younger age. This could be particularly helpful with children having weaknesses in semantic representations.

However, we must indicate at least three limitations of this study. First, the transfer effects of our training need to be explored by assessing comprehension of other types of figurative language. Second, there was no control group, and third, we had no feedback on whether M.M.'s improved capabilities adequately transferred to metaphor comprehension in everyday life conversation. These issues and the solidity of our training effects should be investigated in future research.

\section{ETHICS STATEMENT}

The Head of the Dipartimento di Pediatria e Neuropsichiatria Infantile (Un di Roma "Sapienza") (Department of Pediatrics and Child Neuropsychiatry, Un of Rome "Sapienza"), where the study described in this article has

${ }^{3}$ The APL subtest on figurative language includes 4 items for "verbal metaphors" and 4 items for "visual metaphors." Despite the label "metaphor," the test items mostly consist of idioms. The percentages of correct answers of Figure 1A are computed both in each subpart and in the total (8 items).

${ }^{4}$ The verbal items are given a score of 1 if the answer is metaphorical but not fully elaborate, and a score of 2 if it provides a more elaborate explanation. For instance,for the Italian item "Mario ha sempre la luna storta" (English equivalent: "Mario is always in a bad mood"), if the answer is "Mario reacts badly", it is scored 1. If the answer is "Mario is always irritated", it is scored 2. From the initial diagnosis to the follow-up assessment M.M. moved from 0 to 1 correct answer for visual metaphors and from one level 1 score to two level 2 scores for verbal metaphors. 
been conducted provided the ethical approval. The ethical approval was obtained after the parents of the treated child gave their written, informed consent to the assessment and treatment of their child. The parents of the treated child have been informed throughout the whole process of assessment and treatment.

\section{REFERENCES}

American Psychiatric Association (2000). Diagnostic and Statistical Manual of Mental Disorders, 4th Edn. Washington, DC: TextRevision.

American Psychiatric Association (2013). Diagnostic and Statistical Manual of Mental Disorders, 5th Edn. Arlington, VA: American Psychiatric Publishing.

Bishop, D. M. (2003). Test for Reception of Grammar. Version 2 (TROG-2). London: Pearson Assessment (Suraniti, S., Ferri, R., and Neri, V. (eds.). (2011). TROG-2. Firenze: Giunti OS, Italian Edn.).

Constantino, J. N., and Gruber, C. P. (2002). Social Responsiveness Scale (SRS). Los Angeles, CA: Western Psychological Services (Zuddas, A., Di Martino, A., Delitala, L., Anchisi, L., and Melis, G. (2010). SRS. Firenze: Giunti OS, Italian Edn.).

Declercq, C., Baltazart, V., and Didon, D. (2010). Les nuages sont un troupeau de moutons: a quel age les enfants comprennent-ils qu'il n'y pas de moutons dans le ciel? Can. J. Exp. Psychol. 2, 142-152. doi: 10.1037/a0020175

Demorest, A., Silberstein, L., Gardner, H., and Winner, E. (1983). Telling it as isn't: children's understanding of figurative language. Brit. J. Dev. Psychol. 1, 121-134. doi: 10.1111/j.2044-835X.1983.tb00550.x

Dennis, M., Lazenby, A., and Lockyer, L. (2001). Inferential language in high-functioning children with autism. J. Autism Dev. Disord. 31, 47-54. doi: 10.1023/A:1005661613288

Dunn, L. M., and Dunn L. M. (1981). Peabody Picture Vocabulary Test. Circle Pines, MN: American Guidance Service (Stella, G., Pizzoli, C., and Tressoldi, P. E. (2000). Peabody: Test di Vocabolario Ricettivo. Torino: Omega, Italian Edn.).

Gentner, D. (1988). Metaphor as structure-mapping: the relational shift. Child Dev. 59, 47-59. doi: $10.2307 / 1130388$

Gernsbacher, M. A., and Pripas-Kapit, S. R. (2012). Who's missing the point? A commentary on claims that autistic persons have a specific deficit in figurative language comprehension. Metaphor Symb. 27, 93-105. doi: 10.1080/10926488.2012.656255

Happé, F. (1993). Communicative competence and theory of mind in autism: a test of relevance theory. Cognition 48, 101-119. doi: 10.1016/0010-0277(93)90026-R

Happé, F. (1995). Understanding minds and metaphors: insight from the study of figurative language in autism. Metaphor Symb. Act. 10, 275-295. doi: $10.1207 /$ s15327868ms1004_3

Kasirer, A., and Mashal, N. (2014). Verbal creativity in autism: comprehension and generation of metaphorical language in high-functioning autism spectrum disorder and typical development. Front. Hum. Neurosci. 8:615. doi: $10.3389 /$ fnhum.2014.00615

Keil, F. C. (1986). Conceptual domains and the acquisition of metaphor. Cogn. Dev. 1, 73-96. doi: 10.1016/S0885-2014(86)80024-7

Korkman, M., Kirk, U., and Kemp, S. (2007). NEPSY, 2nd Edn. San Antonio, TX: The Psychological Corporation (Urgesi, C., Campanella, F., and Fabbro, F. (2011). NEPSY II. Firenze: Giunti OS, Italian Edn.).

Krug, D. A., and Arick, J. (2003). Krug Asperger's Disorder Index. Pro-Edn. Austin, TX (Nardocci, F., Cangini, A., and Grittani, S. (2007). KADI. Test per la Valutazione/Diagnosi del Disturbo di Asperger. Trento: Erickson, Italian Edn.).

Lord, C., Rutter, M., Dilavore, P. C., and Risi, S. (2000). Autism Diagnostic Observation Schedule. Los Angeles, CA: Western Psychological Services (Tancredi, R., Saccani, M., Persico, A. M., Parrini, B., Igliozzi, R., and Faggioli, R. (2005). Autism Diagnostic Observation Schedule. Firenze: Giunti OS, Italian Edn.).

\section{AUTHOR CONTRIBUTIONS}

SM is responsible for the whole empirical study. He wrote a first draft of the whole manuscript. MP and MO were interlocutors at every stage of the empirical study and the writing and revising process.

Lorusso, M. T. (2007). APL-Medea. Abilità Pragmatiche Del Linguaggio. Firenze: Giunti OS.

Lundgren, K., Brownel, H., Soma, R., and Cayer-Meade, C. (2006). A metaphor comprehension intervention for patients with right hemisphere brain damage: a pilot study. Brain Lang. 99, 60-70. doi: 10.1016/j.bandl.2006. 06.044

Martin, I., and McDonald, S. (2004). An exploration of causes of non-literal problems in individuals with Asperger syndrome. J. Autism Dev. Disord. 34, 311-328. doi: 10.1023/B:JADD.0000029553.52889.15

Mashal, N., and Kasirer, A. (2011). Thinking maps enhance metaphoric competence in children with autism and learning disabilities. Res. Dev. Disabil. 32, 2045-2054. doi: 10.1016/j.ridd.2011.08.012

Melogno, S., D’Ardia, C., Pinto, M. A., and Levi, G. (2012a). Explaining metaphors in high functioning autism spectrum disorder children: a brief report. Res. Autism Spectr. Disord. 6, 683-689. doi: 10.1016/j.rasd.2011.09.005

Melogno, S., D'Ardia, C., Pinto, M. A., and Levi, G. (2012b). Metaphor comprehension in autistic spectrum disorders: case studies of two high-functioning children. Child Lang. Teach. Ther. 2, 177-1888. doi: $10.1177 / 0265659011435179$

Melogno, S., Pinto, M. A., and Levi, G. (2012c). Metaphor and metonymy comprehension in ASD children: a critical review from a developmental perspective. Res. Autism Spectr. Disord. 8, 1289-1296. doi: 10.1016/j.rasd.2012.04.004

Norbury, C. F. (2005). The relationship between theory of mind and metaphor: evidence from children with language impairment and autistic spectrum disorder. Br. J. Dev. Psychol. 23, 383-399. doi: 10.1348/026151005X26732

Persicke, A., Tarbox, J., Ranick, J., and St. Clair, M. (2012). Establishing metaphorical reasoning in children with autism. Res. Autism Spectr. Disord. 6, 913-920. doi: 10.1016/j.rasd.2011.12.007

Pinto, M. A., Melogno, S., and Iliceto, P. (2008). TCM Junior. Test di Comprensione Delle Metafore. Scuola dell'infanzia e Scuola Primaria. Roma: Carocci Faber.

Rundblad, G., and Annaz, D. (2010). The atypical development of metaphor and metonymy comprehension in children with autism. Autism 14, 29-47. doi: $10.1177 / 1362361309340667$

Vosniadou, S. (1987). Children and metaphors. Child Dev. 58, 870-885. doi: $10.2307 / 1130223$

Vulchanova, M., Saldana, D., Chahboun, S., and Vulchanov, V. (2015). Figurative language processing in atipical populations: the ASD perspective. Front. Hum. Neurosci. 24, 1-11. doi: 10.3389/fnhum.2015.00024

Wechsler, D. (1991). Wechsler Intelligence Scale for Children, 3rd Edn. (WISC-III). (Orsini, A., and Picone, L. (2006). Contributo Alla Taratura Italiana. Firenze: OS, Italian Edn.).

Winner, E. (1998). The Point of the Words. Harvard: Harvard University Press.

Conflict of Interest Statement: The authors declare that the research was conducted in the absence of any commercial or financial relationships that could be construed as a potential conflict of interest.

Copyright (c) 2017 Melogno, Pinto and Orsolini. This is an open-access article distributed under the terms of the Creative Commons Attribution License (CC BY). The use, distribution or reproduction in other forums is permitted, provided the original author(s) or licensor are credited and that the original publication in this journal is cited, in accordance with accepted academic practice. No use, distribution or reproduction is permitted which does not comply with these terms. 